\title{
A split methyl halide transferase AND gate that reports by synthesizing an indicator gas
}

Emily M. Fulk ${ }^{1, \ddagger}$, Dongkuk Huh ${ }^{2, \ddagger}$, Joshua T. Atkinson², Margaret Lie², Caroline A. Masiello ${ }^{2,3,4}$, and Jonathan J. Silberg ${ }^{2,5,6}$ *

Author affiliations:

1. Systems, Synthetic, and Physical Biology Graduate Program, Rice University, 6100 Main Street, MS-180, Houston, Texas 77005

2. Department of Biosciences, Rice University, 6100 Main Street, MS-140, Houston, TX, 77005

3. Department of Earth, Environmental and Planetary Sciences, Rice University, MS 126, Houston TX 77005.

4. Department of Chemistry, Rice University, 6100 Main Street, MS 60, Houston, TX 77005

5. Department of Bioengineering, Rice University, 6100 Main Street, MS-142, Houston, TX, 77005

6. Department of Chemical and Biomolecular Engineering, Rice University, 6100 Main Street, MS-362, Houston, TX, 77005

¥These authors contributed equally to this work.

*To whom correspondence should be addressed: Jonathan J. Silberg, Biosciences Department, 6100 Main Street, Houston TX 77005; Tel: 713-348-3849; Email: joff@rice.edu 
Table S1. Constructs used in this study. $\operatorname{sMHT}(1-x)$ and $\operatorname{sMHT}(y-230)$ indicate the amino acids of $B m-\mathrm{MHT}$ included in each sMHT fragment.

\begin{tabular}{|c|c|c|c|c|c|c|}
\hline \multirow[b]{2}{*}{ Plasmid } & \multirow[b]{2}{*}{ Description } & \multicolumn{2}{|c|}{ ORF1 } & \multicolumn{2}{|c|}{ ORF2 } & \multirow[b]{2}{*}{ Addgene ID } \\
\hline & & $\begin{array}{l}\text { Promoter } \\
\text { (Regulation) }\end{array}$ & ORF & $\begin{array}{l}\text { Promoter } \\
\text { (Regulation) }\end{array}$ & ORF & \\
\hline pEMF034 & sMHT-113 & PLtetO-1 (TetR) & $\begin{array}{l}\text { sMHT(1-113)- } \\
\text { SYNZIP17 }\end{array}$ & PLtetO-1 (TetR) & $\begin{array}{c}\text { SYNZIP18- } \\
\text { sMHT(114-230) }\end{array}$ & 157631 \\
\hline pEMF035 & sMHT-67 & PLtetO-1 (TetR) & $\begin{array}{l}\text { sMHT(1-67)- } \\
\text { SYNZIP17 }\end{array}$ & PLtetO-1 (TetR) & $\begin{array}{l}\text { SYNZIP18- } \\
\text { sMHT(68-230) }\end{array}$ & 157632 \\
\hline pEMF036 & sMHT-129 & PLtetO-1 (TetR) & $\begin{array}{l}\text { sMHT(1-129)- } \\
\text { SYNZIP17 }\end{array}$ & PLtetO-1 (TetR) & $\begin{array}{c}\text { SYNZIP18- } \\
\text { sMHT(130-230) }\end{array}$ & 157633 \\
\hline pEMF037 & $\begin{array}{l}\text { Wild type } \\
\text { (WT) control }\end{array}$ & PLtetO-1 (TetR) & Bm-MHT & - & - & 157634 \\
\hline pEMF038 & $\begin{array}{l}\text { Empty vector } \\
(E V) \text { control }\end{array}$ & PLtetO-1 (TetR) & - & - & - & 157635 \\
\hline pEMF047 & $\begin{array}{l}\text { sMHT-113 } \\
\text { F1 only }\end{array}$ & PLtetO-1 (TetR) & $\begin{array}{l}\text { sMHT(1-113)- } \\
\text { SYNZIP17 }\end{array}$ & - & - & 157636 \\
\hline pEMF044 & $\begin{array}{l}\text { sMHT-113 } \\
\text { F2 only }\end{array}$ & PLtetO-1 (TetR) & $\begin{array}{c}\text { SYNZIP18- } \\
\text { sMHT(114-230) }\end{array}$ & - & - & 157637 \\
\hline $\mathrm{pDH} 013$ & $\begin{array}{l}\text { sMHT-113 } \\
\text { GFP/RFP }\end{array}$ & PLtetO-1 (TetR) & $\begin{array}{l}\text { sMHT(1-113)- } \\
\text { SYNZIP17- } \\
\text { GFPmut3 }\end{array}$ & Placo-1 (Lacl) & $\begin{array}{c}\text { mRFP1- } \\
\text { SYNZIP18- } \\
\text { sMHT(114-230) }\end{array}$ & 157638 \\
\hline pDH001 & $\mathrm{P}_{\mathrm{T7}}-\mathrm{Bm}-\mathrm{MHT}$ & T7 (Lacl) & $B m-\mathrm{MHT}$ & - & - & 157639 \\
\hline $\mathrm{pDH003}$ & $\begin{array}{c}\mathrm{P}_{\mathrm{T} 7-\mathrm{SMHT}} \\
113\end{array}$ & T7 (Lacl) & $\begin{array}{l}\text { sMHT(1-113)- } \\
\text { SYNZIP17 }\end{array}$ & T7 (Lacl) & $\begin{array}{c}\text { SYNZIP18- } \\
\text { sMHT(114-230) }\end{array}$ & 157640 \\
\hline pDH006 & $\begin{array}{c}\text { sMHT-113 } \\
\text { SYNZIP18 } \\
\text { only } \\
\end{array}$ & T7 (Lacl) & sMHT(1-113) & T7 (Lacl) & $\begin{array}{c}\text { SYNZIP18- } \\
\text { sMHT(114-230) }\end{array}$ & 157641 \\
\hline pDH007 & $\begin{array}{l}\text { sMHT-113 } \\
\text { CheAY }\end{array}$ & T7 (Lacl) & $\begin{array}{l}\text { sMHT(1-113)- } \\
\text { CheA }\end{array}$ & T7 (Lacl) & $\begin{array}{c}\text { CheY- } \\
\text { sMHT(114-230) }\end{array}$ & 157642 \\
\hline pDH008 & $\begin{array}{l}\text { sMHT-113 } \\
\text { CheY only }\end{array}$ & T7 (Lacl) & sMHT(1-113) & T7 (Lacl) & $\begin{array}{c}\text { CheY- } \\
\text { sMHT(114-230) }\end{array}$ & 157643 \\
\hline pDH009 & $\begin{array}{l}\text { sMHT-113 } \\
\text { GRX2 }\end{array}$ & T7 (Lacl) & $\begin{array}{l}\text { sMHT(1-113)- } \\
\text { GRX2 }\end{array}$ & T7 (Lacl) & $\begin{array}{c}\text { sMHT(114-230)- } \\
\text { GRX2 }\end{array}$ & 157644 \\
\hline pDH010 & $\begin{array}{c}\text { sMHT-113 } \\
\text { GRX2-C37A } \\
\text { mutant }\end{array}$ & T7 (Lacl) & $\begin{array}{l}\text { sMHT(1-113)- } \\
\text { GRX2_C37A }\end{array}$ & T7 (Lacl) & $\begin{array}{l}\text { sMHT(114-230)- } \\
\text { GRX2_C37A }\end{array}$ & 157645 \\
\hline pDH011 & $\begin{array}{l}\text { sMHT-113 } \\
\text { FKBP/FRB }\end{array}$ & T7 (Lacl) & $\begin{array}{l}\text { sMHT(1-113)- } \\
\text { FKBP }\end{array}$ & T7 (Lacl) & $\begin{array}{c}\text { FRB-sMHT(114- } \\
230)\end{array}$ & 157646 \\
\hline $\mathrm{pDH} 012$ & $\begin{array}{c}\text { P14-sMHT- } \\
113\end{array}$ & $\begin{array}{c}\mathrm{P} 14^{1} \\
\text { (constitutive) }\end{array}$ & $\begin{array}{l}\text { sMHT(1-113)- } \\
\text { SYNZIP17 }\end{array}$ & $\begin{array}{c}\mathrm{P} 14^{1} \\
\text { (constitutive) }\end{array}$ & $\begin{array}{c}\text { SYNZIP18- } \\
\text { sMHT(114-230) }\end{array}$ & 157647 \\
\hline
\end{tabular}


A

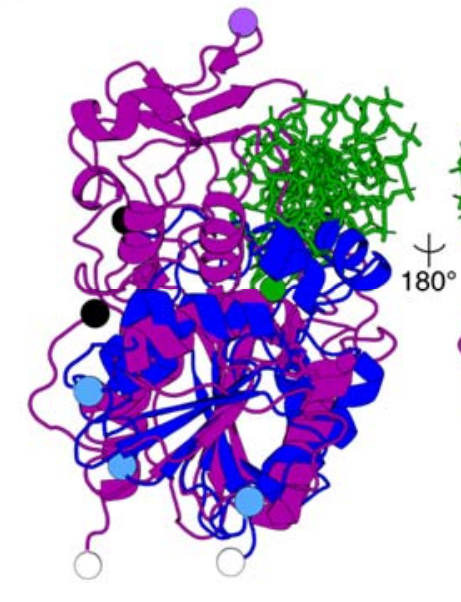

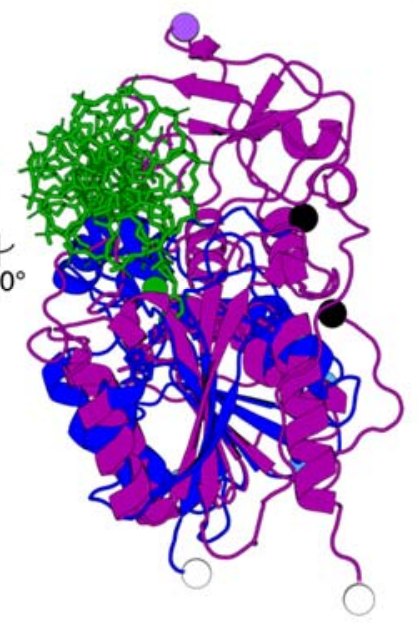

B
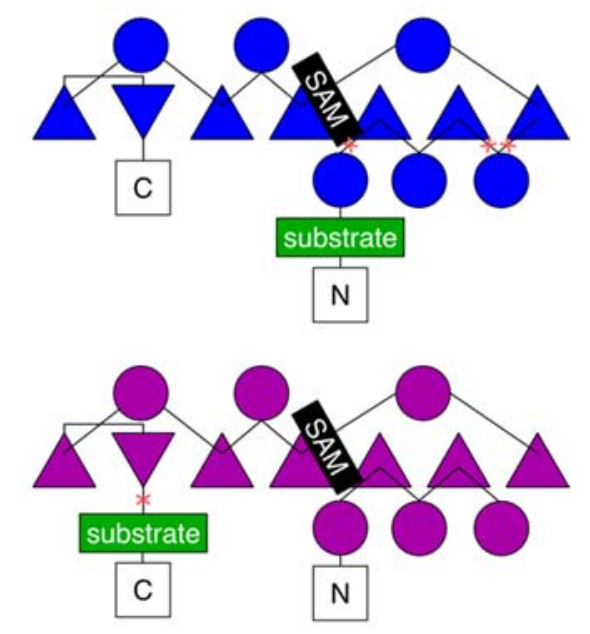

Figure S1. Comparison of methyl-halide and C5-DNA methyltransferase structures. (A) Tertiary structures of Arabidopsis thaliana MHT (blue) and the C5-DNA methyltransferase from Haemophilus haemolyticus M.Hhal (purple). Structures of MHT (PDB: $3 \mathrm{LCC})^{2}$ and M.Hhal (PDB: $\left.1 \mathrm{MHT}\right)^{3}$ were aligned using the MATT alignment algorithm ${ }^{4}$ revealing a core overlapping region of 138 residues (RMSD of $3.317 \AA$ ). The proposed halide ion substrate position is shown in the MHT (green sphere) ${ }^{2}$. The DNA substrate of M.Hhal (green sticks) can be seen adjacent to the halide ion. The S-adenosyl homocysteine products are shown as sticks in colors matching their corresponding structure. $\mathrm{N}$ - and C-termini are shown as black and white spheres, respectively. Split sites are labelled as spheres for MHT (light blue) and M.Hhal (light purple) ${ }^{5}$. (B) Topology diagrams from the Rossmann-fold core regions of MHT (blue) and M.Hhal (purple) methyltransferases. Beta sheets are shown as triangles, alpha helices are shown as circles, and loop regions are shown as lines. Split sites are shown as red crosses. The SAM and substrate binding regions are shown as black rectangles. For simplicity only secondary structure elements from the Rossmann-fold regions are included. 


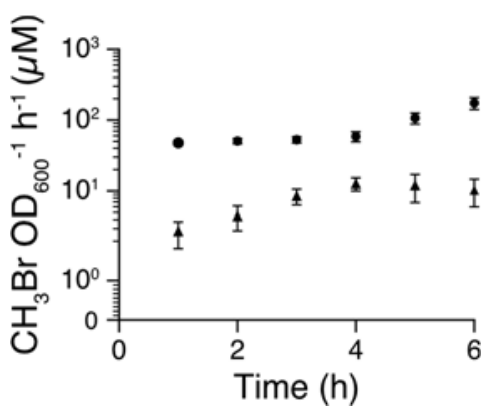

Figure S2. Effect of temperature on the rate of $\mathrm{CH}_{3} \mathrm{Br}$ production by cells expressing SMHT-113 fragments fused to SYNZIP17 and SYNZIP18. The rate of $\mathrm{CH}_{3} \mathrm{Br}$ accumulation ( $\mu \mathrm{M} / \mathrm{OD}_{600} /$ hour) measured at different temperatures reveals a rate after 6 hours that is significantly higher at $30^{\circ} \mathrm{C}$ (circles) compared with $37^{\circ} \mathrm{C}$ (triangles) $\left(p=2.3 \times 10^{-3}\right)$. Data represent the average of 3 biological replicates, with error bars representing +/- 1 standard deviation. Significance was evaluated using a two-sided, independent t-test. 


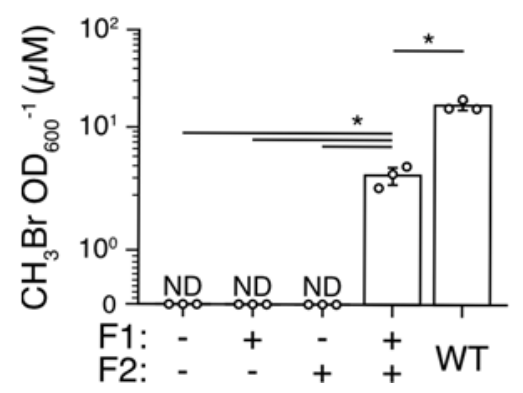

Figure S3. $\mathrm{CH}_{3} \mathrm{Br}$ production from cells expressing one or both sMHT-SYNZIP fragments. $\mathrm{OD}_{600}$-normalized $\mathrm{CH}_{3} \mathrm{Br}(\mu \mathrm{M})$ accumulation in the headspace of cultures after 24 hour incubations at $30^{\circ} \mathrm{C}$ of cells containing a vector that does not express sMHT113 fragments (-/-) and vectors that express F1-SYNZIP17 only (+/-), SYNZIP18-F2 only $(-/+)$, F1-SYNZIP17 and SYNZIP18-F2 (+/+), or Bm-MHT (WT). The amount of $\mathrm{CH}_{3} \mathrm{Br}$ produced by cells expressing both SMHT-SYNZIP fragments was significantly higher than cells expressing neither fragment, F1-SYNZIP17 only, or SYNZIP18-F2 only $(p=2.21 x$ $10^{-3}$ for each). Cells expressing $\mathrm{Bm}-\mathrm{MHT}$ produced significantly more $\mathrm{CH}_{3} \mathrm{Br}$ than cells expressing F1-SYNZIP17 and SYNZIP18-F2 $\left(p=5.11 \times 10^{-4}\right)$. Under our experimental conditions, the detection limit for $\mathrm{CH}_{3} \mathrm{Br}$ was approximately $0.016 \mu \mathrm{M}$ in the liquid phase. Each data point represents the average of 3 biological replicates, with error bars representing +/- 1 standard deviation. Individual replicates are shown as circles. Significance differences $(p<0.01)$ noted with an asterisk were calculated using a twosided, independent t-test. ND = none detected. 
A

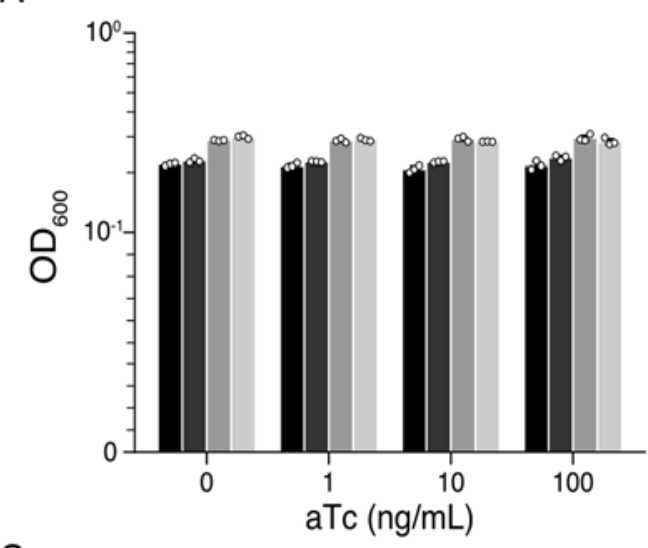

C

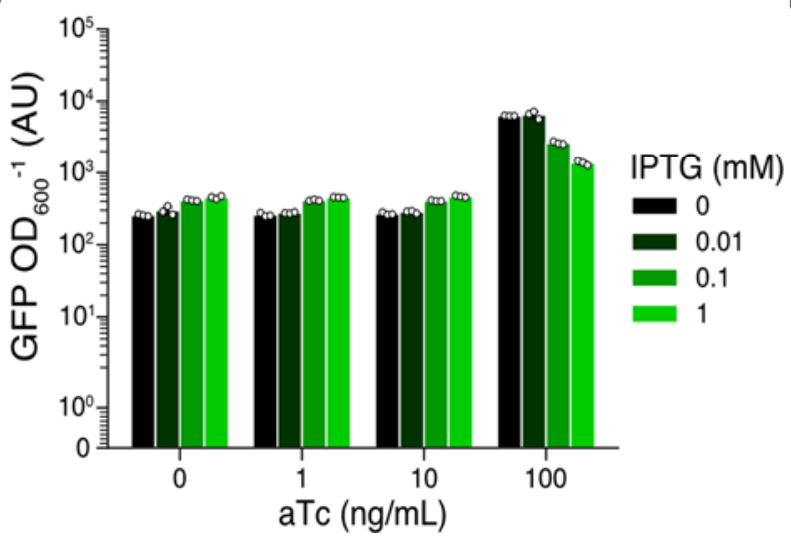

B
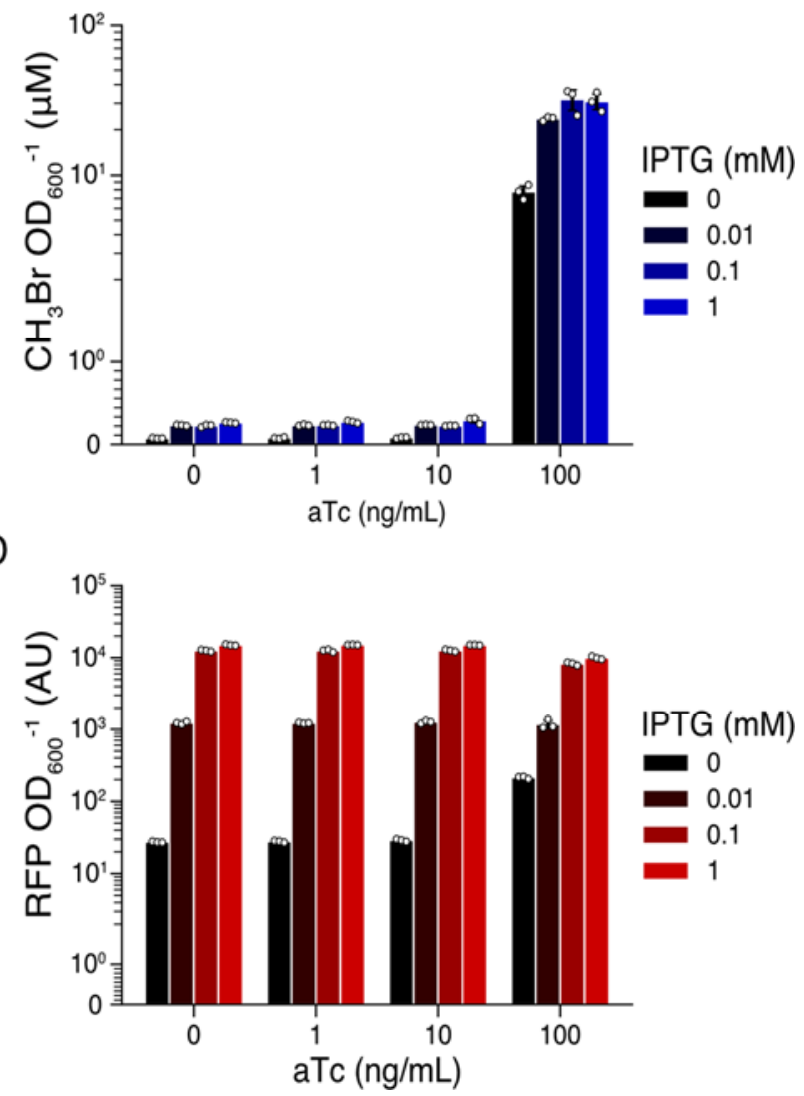

Figure S4. Two input AND gate measurements. (A) $\mathrm{OD}_{600}$ values for cultures grown in the presence of different aTc $(0,1,10,100 \mathrm{ng} / \mathrm{mL})$ and IPTG $(0,0.01,0.1$, and $1 \mathrm{mM})$ concentrations. All cultures grew to a similar $\mathrm{OD}_{600}(\mathrm{p}>0.01)$. (B) $\mathrm{CH}_{3} \mathrm{Br}(\mu \mathrm{M})$ accumulation in the same cultures after 24 hours. The relative $\mathrm{CH}_{3} \mathrm{Br}$ production was calculated as the ratio of $\mathrm{CH}_{3} \mathrm{Br}$ concentration to $\mathrm{OD}_{600}$ to account for variability in cell growth. (C) GFP fluorescence (AU, arbitrary units) in the same cultures after 24 hours. GFP fluorescence was calculated as the ratio of green emission to $\mathrm{OD}_{600}$ to account for variability in cell growth. (D) RFP fluorescence (AU) in the same cultures. RFP fluorescence was calculated as the ratio of red emission to $\mathrm{OD}_{600}$ to account for variability in cell growth. Each data point represents the average of 3 biological replicates, with error bars representing +/- 1 standard deviation. Individual replicates are shown as circles. Significance values were calculated using a two-sided, independent t-test. 
A

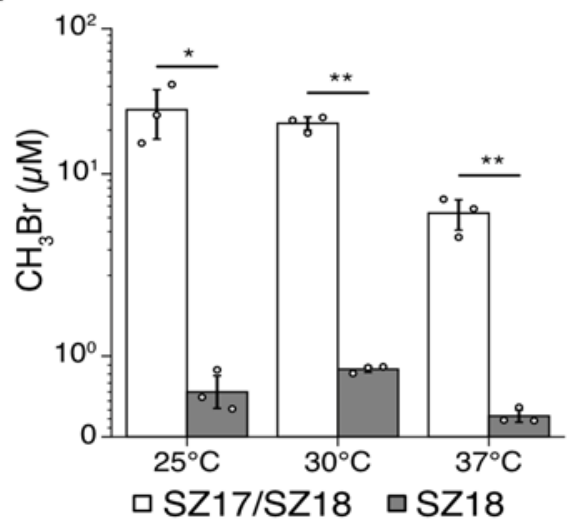

C

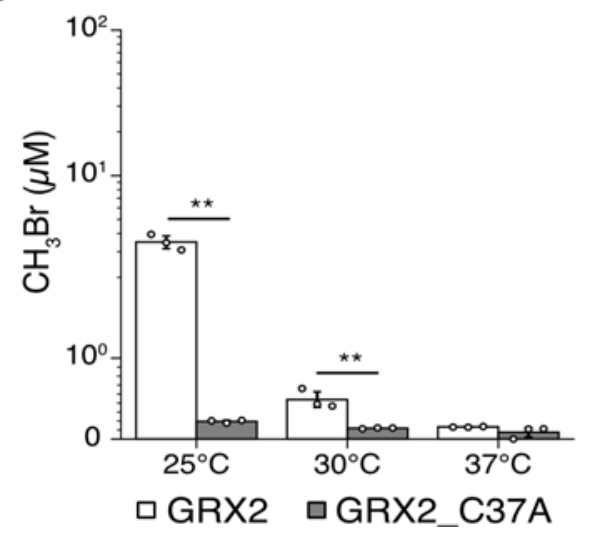

B

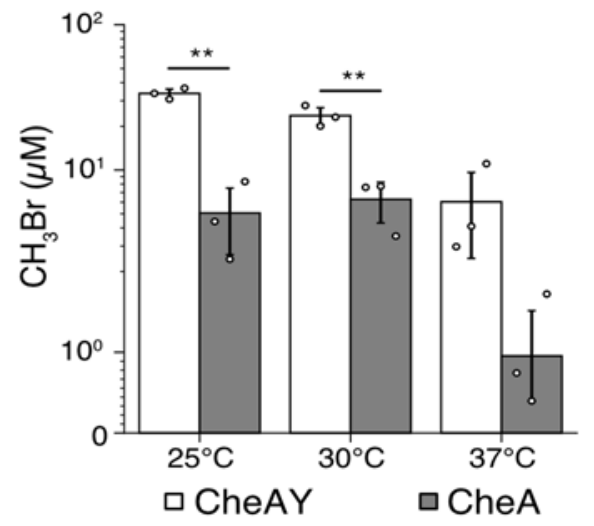

Figure S5. Effect of temperature on the activities of SMHT-113 fusion proteins. $\mathrm{CH}_{3} \mathrm{Br}$ production at 25,30 , and $37^{\circ} \mathrm{C}$ by $(\mathbf{A})$ sMHT-SYNZIP17/18 (SZ17/18) fusions, (B) SMHT-CheAY fusions, and (C) SMHT-GRX2 fusions. White bars represent constructs with both SMHT fragments tethered to interacting partner proteins. Gray bars represent constructs where $\mathrm{F} 1$ is expressed without fusion to the interacting protein partner (SZ18 and CheA in panels $A$ and $B$ respectively) or where the protein partner's ability to dimerize has been removed via mutation (GRX2_C37A in panel C). All constructs showed a significant $(\mathrm{p}<0.05)$ decrease in $\mathrm{CH}_{3} \mathrm{Br}$ production between dimerizing and nondimerizing constructs at 25 and $30^{\circ} \mathrm{C}$. Data represent the average of 3 biological replicates, with error bars representing +/- 1 standard deviation. Individual replicates are shown as circles. Significance values $\left({ }^{*} p<0.05 ;{ }^{* *} p<0.01\right)$ were calculated using a twosided, independent t-test. 


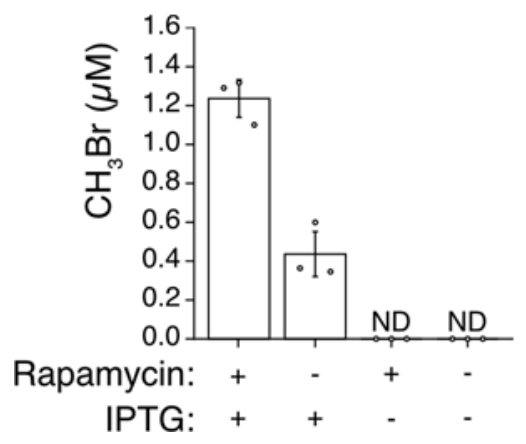

Figure S6. Effect of IPTG and rapamycin on $\mathrm{CH}_{3} \mathrm{Br}$ production. The effect of rapamycin $(100 \mu \mathrm{M})$ and IPTG $(100 \mu \mathrm{M})$ on $\mathrm{CH}_{3} \mathrm{Br}$ synthesis by cells containing a vector for Lacl-controlled coexpression of F1-FKBP and FRB-F2. $\mathrm{CH}_{3} \mathrm{Br}$ production was measured following incubation at $37^{\circ} \mathrm{C}$ for 24 hours in closed vials. The gas production in the presence of both IPTG and rapamycin was significantly higher than that observed with IPTG or rapamycin alone $(p<0.01)$. Data represent the average of 3 biological replicates, with error bars representing +/- 1 standard deviation. Individual replicates are shown as circles. Significance values $\left({ }^{*} p<0.01\right)$ were calculated using a two-sided, independent t-test. ND = none detected. 


\section{Supplementary Methods}

Gas production rates by SMHT-113-SYNZIP at varying temperatures. To characterize $\mathrm{CH}_{3} \mathrm{Br}$ synthesis rates, E. coli MG1655 harboring a construct that constitutively expresses both sMHT-113-SYNZIP fragments was grown to exponential phase in M63 media with streptomycin $(100 \mu \mathrm{g} / \mathrm{mL}) .1 \mathrm{~mL}$ culture was diluted to an $\mathrm{OD}_{600}=0.1$ in a capped vial, cells were incubated at the indicated temperatures for one hour, and indicator gas was measured using GC-MS. Following each measurement, vials were uncapped, the $\mathrm{OD}_{600}$ was measured, and the vial was aerated (20 times with $50 \mathrm{~mL}$ of air each time) to purge $\mathrm{CH}_{3} \mathrm{Br}$ molecules in the gas and liquid phase. Each vial was recapped, incubated for an hour, and the sampling/purging was repeated.

Gas production from cells expressing individual SMHT-SYNZIP fragments. To characterize $\mathrm{CH}_{3} \mathrm{Br}$ production by cells expressing one or both of the sMHT-SYZNIP fragments, we transformed E. coli MG1655 with each construct and prepared cultures in sealed vials as in other gas production experiments (see Methods). Cultures were incubated for 24 hours at $30^{\circ} \mathrm{C}$ before measuring $\mathrm{CH}_{3} \mathrm{Br}$ production and $\mathrm{OD}_{600}$.

Gas production rates by SMHT-113 fusions at varying temperatures. To evaluate the effect of temperature on $\mathrm{CH}_{3} \mathrm{Br}$ production by sMHT fused to SYNZIP, CheAY, and GRX2 partners, gas production by $E$. coli XL1 harboring each sMHT-partner fusion as well as the corresponding non-dimerizing control was measured. Cultures in M63 in sealed vials were prepared as in other gas production experiments (see Methods), protein expression was induced with IPTG $(1 \mathrm{mM})$, and cultures incubated at 25,30 , or $37^{\circ} \mathrm{C}$ for 18 hours before measuring $\mathrm{CH}_{3} \mathrm{Br}$ accumulation. 
Gas production by SMHT-FKBP/FRB fusions +/- IPTG and rapamycin. To assess the background production of $\mathrm{CH}_{3} \mathrm{Br}$ by sMHT-FKBP/FRB, E. coli CS50 cultures expressing sMHT-113 FKBP/FRB fusions were prepared as previously described (see Methods). At mid-log phase, IPTG $(1 \mathrm{mM})$ and/or rapamycin $(100 \mu \mathrm{M})$ was added, and cultures incubated for 24 hours at $37^{\circ} \mathrm{C}$ before $\mathrm{CH}_{3} \mathrm{Br}$ measurement. 


\section{References}

(1) Mutalik, V. K., Guimaraes, J. C., Cambray, G., Lam, C., Christoffersen, M. J., Mai, Q.-A., Tran, A. B., Paull, M., Keasling, J. D., Arkin, A. P., and Endy, D. (2013) Precise and reliable gene expression via standard transcription and translation initiation elements. Nat. Methods 10, 354-360.

(2) Schmidberger, J. W., James, A. B., Edwards, R., Naismith, J. H., and O'Hagan, D. (2010) Halomethane biosynthesis: structure of a SAM-dependent halide methyltransferase from Arabidopsis thaliana. Angew. Chem. Int. Ed Engl. 49, 3646-3648.

(3) Klimasauskas, S., Kumar, S., Roberts, R. J., and Cheng, X. (1994) Hhal methyltransferase flips its target base out of the DNA helix. Cell 76, 357-369.

(4) Menke, M., Berger, B., and Cowen, L. (2008) Matt: Local Flexibility Aids Protein Multiple Structure Alignment. PLOS Comput. Biol. 4, e10.

(5) Chaikind, B., Kilambi, K. P., Gray, J. J., and Ostermeier, M. (2012) Targeted DNA Methylation Using an Artificially Bisected M.Hhal Fused to Zinc Fingers. PLoS ONE 7, e44852. 